\title{
Hot Spot
}

National Cancer Institute

\section{Source}

National Cancer Institute. Hot Spot. NCI Thesaurus. Code C19744.

A center of high activity within a larger area of low activity. The term is applied to

different things in different areas of study. 